\title{
A Classroom Investment Coordination Experiment
}

Denise Hazlett

Whitman College, USA

\begin{abstract}
In this classroom experiment students represent firms that make investment decisions. They play a repeated game with each firm privately choosing its level of investment. Participating in the experiment helps students understand theories that posit coordination failure as the cause of economic fluctuations. Students see that when firms expect a recession, their resulting low levels of investment actually cause a recession. Likewise, when firms expect an expansion, their resulting high levels of investment cause an expansion. The experiment can be used in undergraduate principles or intermediate macroeconomics classes of 8-60 students. It does not require computers and takes approximately 50 minutes to run and discuss.
\end{abstract}

\section{Introduction}

A classroom experiment puts students in a controlled environment and asks them to make economic decisions. Their decisions become the data the class later analyses. This experiment uses a hands-on approach to help students see how uncertainty can cause and prolong a recession. The paper describes how to run the experiment and follow it up with a discussion of policies designed to reduce the uncertainty that can cause economic fluctuations.

\section{Description of the experiment}

Students represent strategically interdependent firms who, in each round of the game, simultaneously and privately decide their level of investment in new factories and equipment. Firms can choose either a high $(\mathrm{H})$ or a low $(\mathrm{L})$ level of investment. A firm that chooses a high level can produce more goods. However, households could afford to purchase these new goods only if national income rises. 
National income would rise if other firms simultaneously chose to invest at a high level, thus raising aggregate demand. However, if other firms invest at a low level, generating low aggregate demand, then a firm that invests at a high level will have incurred a large expense without a corresponding increase in revenue. In contrast, a firm that invests at a low level avoids the expense of high investment. So, this latter firm does not suffer as much when aggregate demand is low. Thus, unless the other firms in the economy invest at a high level, a firm does better to choose a low level of investment.

The instructor forms the class into groups of four to play the game described in Table 1. Each group represents an economy. Having multiple groups allows the class to generate results for several economies simultaneously (see Appendix A for the instructions). A printable version of the instructions and a student recordkeeping sheet can be accessed online by going to http://people.whitman.edu/ hazlett/econ/.

Table 1: Payoffs for the investment game

\begin{tabular}{lllll}
\hline $\begin{array}{l}\text { Of the } 3 \text { other firms in your group, } \\
\text { the number who choose } \mathrm{H}\end{array}$ & 0 & 1 & 2 & 3 \\
Your profits if you choose $\mathrm{H}$ & 0 & 1 & 3 & 5 \\
Your profits if you choose $\mathrm{L}$ & 2 & 3 & 4 & 4 \\
\hline
\end{tabular}

Table 1 describes the payoffs to one firm, depending on what the three other firms in the group choose. Small, individually wrapped candies such as Hershey's Kisses serve as the payoffs. The first column in Table 1 shows a firm's profits when no one else in the group chooses $\mathrm{H}$. In this case, a firm that chooses $\mathrm{H}$ would get a profit of zero. If the firm had instead chosen $\mathrm{L}$, it could have avoided the futile expense of high investment during a recession, thereby earning profits of 2 . Similarly, the last column shows the firm's profits if all three of the other players choose H. The firm would earn 5 if it also chooses $\mathrm{H}$, but only 4 if it chooses L. With an expansion underway, the firm does better by investing at a high rather than low level. The middle columns describe the other possible situations in which a firm could find itself.

The one-shot game has two pure-strategy Nash equilibria. In one equilibrium, all of the firms invest at a low level, causing a recession. In the other equilibrium, all of the firms invest at a high level, causing an expansion. The various other possible outcomes generate intermediate levels of aggregate output. In each case, the more firms that choose $\mathrm{H}$, the higher the combined profits of the firms. Moreover, everyone choosing $\mathrm{H}$ produces the highest possible profit for each individual firm. However, because choosing $\mathrm{H}$ entails risk, coordinating on this optimal outcome 
may prove difficult. A firm must believe that everyone else in the group will choose $\mathrm{H}$ for its best response to be $\mathrm{H}$.

Students will repeat the game several times, and the instructor can change group members for each round. Repeated play generates a series of data for each economy, so the class can compare these performances through the rounds. What is more, repeated play captures the continuing nature of the investment game that real firms play. I suggest running approximately 6-8 rounds. The instructor does not tell students how many rounds they will play, thus generating the equivalent of an infinitely repeated game with a discount rate equal to the probability of the game ending that round.1 For simplicity, each round is completely independent from the previous one. That is, an investment decision affects payoffs in this round, but not in the future. Essentially, the capital produced by investment completely depreciates before the next round.

Changing the group members allows the instructor to include students who did not initially join a group, either because the class was not divisible by four or because a student showed up late. It works well to have 1-3 students sitting out each round, waiting to get switched into an economy. When they first join an economy, the unknown element they represent generates uncertainty, mimicking the real-world effect of new firms starting up. Similarly, switching a few members between groups can change their expectations and trigger fluctuations in aggregate investment.

In order to keep students focused on their decisions in each round (and also to avoid overwhelming them with too much candy), only one round provides actual payoffs. The instructor announces before the experiment begins that a die roll at the end of the experiment will determine which round provides payoffs. After an experiment that lasted more than six rounds, the instructor rolls the die twice, once to determine whether the payoffs will come from the first or last half of the experiment, and again to determine the payoff round. Students who were sitting out during that round collect the average payoff for the class as a whole. Note that the maximum possible payoff provides five candies per students. A one-pound bag of Hershey's Kisses contains 100 pieces, the maximum payoff for a class of 20 students.

In each round, students privately record their investment choices and the names of the people in their group (see Appendix B for this record-keeping sheet). Once all the students have finished recording their choices for a round, the instructor asks each to report this choice to the class. Students then record their group's results, and their own profit for that round. In order to track each firm's investment level and each economy's performance through the rounds, the instructor uses the 
board to display the results. The instructor can then ask the class in a follow-up discussion to interpret how each economy performed. For instance, no firms choosing $\mathrm{H}$ generates the equivalent of a severe recession in that round. Similarly, one firm choosing $\mathrm{H}$ generates a mild recession, two choosing $\mathrm{H}$ generates an intermediate outcome, three choosing $\mathrm{H}$ generates a mild expansion, and all four choosing $\mathrm{H}$ generates a strong expansion.

In the initial rounds, the instructor does not allow students to talk directly to each other about the game. This restriction on direct communication reflects the physical and legal limitations on communication between firms in an actual economy. However, instructors can lead a general class discussion between rounds, as students report their choices. This discussion mimics the indirect communication between firms provided by business newspapers and trade publications. The instructor asks a few students to explain the reasoning behind their choices, much like a newspaper reporter interviewing a firm's manager. In response, some students explain their concerns about the risk involved in choosing $\mathrm{H}$. Others describe their own choice of $\mathrm{H}$ as a signal that they would like to see all the members of their group choose $\mathrm{H}$, to everyone's benefit. This indirect communication can influence expectations, thereby affecting future choices. For instance, a wave of optimism about the investment climate might hit a group in which one or more members make a veiled plea for everyone to choose H.Likewise, a group in which members worry aloud about the riskiness of $\mathrm{H}$ might suffer a bout of pessimism.

In the last round or two, the instructor allows students to talk directly to each other. They can then make statements, and even promises, about how they intend to play. However, they would still record their choices privately, and have no method for enforcing any promises. Direct communication generally improves coordination, producing higher levels of investment. This result inspires discussion of possible changes in economic structure that promote coordination of investment. Such changes could include advances in information technology, for instance.

The instructor also makes changes that typically cause coordination to break down. For instance, the instructor takes one or two individuals who have persistently played $L$ and substitutes them into a group that has historically achieved high levels of coordination. Members of that group who previously played $\mathrm{H}$ often switch to $L$. The resulting recession promotes discussion of how a sudden lack of confidence in the economy can have dire consequences for investment levels. This discussion can move on to specific ways policy makers attempt to maintain confidence and reduce uncertainty about the investment climate. 
I recommend waiting to form the groups until after students have made their first-round choices. Not knowing who is in their economy tends to keep students from signalling each other while the instructor is busy reading the instructions to the class and dealing with student questions. I also recommend letting students know who will be in their group before each subsequent round, so that the past history of play affects current choices.

Early on, some students may have problems deciphering how one firm's profit depends on the actions of the other firms in the group.I therefore suggest that after all of the members of a group finish reporting their choices, the instructor ask the class to calculate the profit earned by each firm in that group. Having the class work this exercise aloud a few times ensures that everyone eventually understands how to determine profits. Recording these profits on the board provides a reference for those students struggling to understand. For example, Table 2 shows the results from the first two rounds for a particular introductory macroeconomics course with 20 students. This table displays the profit for each group member, as the instructor would write it on the board. Note that in this particular class, every possible combination of play appears within two rounds. After a round or two, the instructor asks whether anyone needs more help figuring out how the payoffs work. Once everyone understands, the instructor can stop writing the payoffs, and simply record the investment choices.

Table 2: Example results, including profits, for the first two rounds

\begin{tabular}{lccccc}
\hline Round & Group 1 & Group 2 & Group 3 & Group 4 & Group 5 \\
\hline 1 & L H H H & L L L L & L L L L & L L L H & L L H H \\
& $4,3,3,3$ & $2,2,2,2$ & $2,2,2,2$ & $3,3,3,0$ & $4,4,1,1$ \\
2 & $\mathrm{H} \mathrm{HHH}$ & $\mathrm{L} \mathrm{H} \mathrm{H} \mathrm{L}$ & L H L H & H H L H & L H L H \\
& $5,5,5,5$ & $4,1,1,4$ & $4,1,4,1$ & $3,3,4,3$ & $4,1,4,1$ \\
\hline
\end{tabular}

When recording the results on the blackboard, the instructor preserves the order that students report their decisions within each group. Then, a glance down a column shows a particular student's decisions in every round.

For classes larger than about 32, the instructor could save time by recording on the board the results from a subset of five groups, rather than all of the groups. Of course, everyone else would still take a moment after each round to report their choices to the other members of their group, and every student would receive payoffs. Having five groups report all of their results provides enough visual information for the class to compare how different economies performed. During the follow-up discussion, groups whose results do not appear on the board can 
briefly report on what their economy did. The class then considers why some groups managed to converge on the high-investment equilibrium, while others converged on the low-investment equilibrium or achieved something in between.

\section{Some comments on payoffs}

For the payoffs, I strongly advise using an item like candy rather than grades or extra credit points. Instructors should especially note that combining a grade for the experimental outcome with a curved course grade would change the experiment into a game where students gain by making somebody else's payoffs lower. That backstabbing game presents a completely different set of incentives than those in an investment coordination situation, where everyone becomes better off if they coordinate.

A cardinal rule of experimentation requires delivering exactly the payoffs promised, no more and no less. If the instructor gives students any reason to believe that they will not receive the payoffs as specified, then they will suspect that they are playing a different game. This suspicion could well affect their choices. So, an instructor who has extra candy remaining after distributing the payoffs, should resist any temptation to dispense the leftovers to this class.

\section{Discussion}

The results can differ widely between groups within a class, and between classes. This variety of results provides rich material for a discussion of the role that expectations play in generating economic fluctuations. A brief background reading for instructors on the topic of expectations and investment coordination appears in Christiano and Fitzgerald (1998). On pages 67-8, these authors present a two-firm game with Pareto ranked Nash equilibria as an example of a potential investment coordination failure. Even in this simplest of games, expectations can act as aggregate shocks driving the business cycle. If each player expects the other to choose $\mathrm{L}$, then this self-fulfilling expectation generates a recession. Likewise, a self-fulfilling expectation of $\mathrm{H}$ generates an expansion.

Instructors need not use terms such as 'Nash equilibrium' or 'coordination game' as they discuss the investment coordination experiment with their students. Nor do students need a background in game theory in order to participate in this experiment. Discussion can focus on the economic interpretation of students' actions, without using any of the language of game theory. However, for students who do know game theory, the instructor can ask them to identify the pure strategy Nash equilibria of the one-shot game. There are two and they are Pareto-ranked. In the Pareto inferior equilibrium all of the firms invest at a low level, 
generating a recession. This strategy profile is a Nash equilibrium because if everyone else chooses $L$, a firm's best response is to choose L. Similarly, if everyone else chooses $\mathrm{H}$, a firm's best response is to choose H. So, in the Pareto superior equilibrium all of the firms invest at a high level, generating an expansion. The normal form for a four-person game cannot be displayed in a single matrix, so the instructor could not show students a simple payoff matrix like that in Christiano and Fitzgerald. However, the instructor can guide students through the analysis by asking them to consider the relevant payoffs in Table 1, which appears in the instructions for the experiment. For instance, the instructor would have students note that when everyone else in the group chooses $\mathrm{H}$, a firm's best response would be to choose $\mathrm{H}$ and get 5 , rather than choosing $\mathrm{L}$ and getting 4 .

During the follow-up discussion, I suggest showing the class a time-series graph of investment as a percentage of gross domestic product (GDP), with the periods of recession highlighted. The Federal Reserve Bank of St. Louis's National Economic Trends (http://www.stls.frb.org/publications/net/) includes such a graph for the United States. These data can either provide an introduction to or a quick review of the volatility of investment, as well as the correlation between investment spending and the business cycle. Given that investment variations often account for most of the downturn in GDP during recessions, the causes of these investment fluctuations take a central role in explaining business cycles.

In the class discussion, the instructor asks students to describe what factors influenced their investment decisions. Students who chose $L$ in the first round often describe it as the safer strategy, with its minimum payoff of 2, versus 0 for $\mathrm{H}$. Those who initially chose $\mathrm{H}$ typically explain that they did so in hopes that others would too, generating more candy for everyone. When students explain how they made their decisions in subsequent rounds, they talk about whether their expectations changed. For instance, over time some students report gaining confidence that others in their group would choose $\mathrm{H}$. On the other hand, some students lose confidence.

These changes in confidence come from several sources: from experience of past play, from insights gleaned during indirect communication between rounds, from group members being switched, and from direct communication. Students sometimes cite the example provided by a group that coordinated on the highinvestment equilibrium, when explaining how they eventually managed to achieve such coordination in their own group. In contrast, having someone who had previously played $\mathrm{L}$ switched into a group that had achieved all $\mathrm{H}$ often disrupts coordination. However, sometimes these people continue to choose H. They explain later that they hoped their history of choosing $\mathrm{H}$ would encourage the new 
member also to choose $\mathrm{H}$. In fact, sometimes the new people who had played $\mathrm{L}$ in the preceding round do indeed switch to $\mathrm{H}$. They describe being inspired by the optimism that comes from getting a fresh start. When it comes to discussing results from the rounds with direct communication, students note that being able to talk to each other generally helped them eliminate their fears about the risk of choosing $\mathrm{H}$.

Once the class has had a chance to consider how changing expectations generate fluctuations in the experimental economies, the instructor can introduce the topic of real-world policy makers' attempts to improve the investment climate by reducing uncertainty. I use this experiment towards the end of my principles of economics or intermediate macroeconomics courses, after covering monetary and fiscal policy. So, in our discussion, I encourage students to consider how a stable investment climate can come in part from policy makers behaving in a predictable and forthright manner. I use the following headline from the 1 February 2001 page A1 Wall Street Journal article to inspire discussion of the actions the Federal Reserve takes to stabilise the business cycle:"Latest Fed Rate Cut Takes on a Contagion of Low Confidence: Amid new Signs of Gloom, Anxiety About Recession Could Be Self-Fulfilling."

\section{Questions for discussion}

The following questions form the basis for the discussion described above.

1. What was the outcome in your group in each round? Did your economy have much variation in total investment over time? How would you interpret the performance of your economy?

2. Why did you choose the investment levels that you did? What factors do you think influenced the decisions of the other people in your group? How did the ability of firms to communicate with each other affect their choices?

3. Do you think the success or failure of firms to coordinate investment decisions in this experiment provides a possible explanation for the actual fluctuations we see in aggregate investment? Explain your reasoning.

4. What sort of changes in the experimental setting could help firms in the experiment achieve the profit-maximising outcome that occurs when everyone invests at a high level? Could real firms possibly achieve something close to this outcome? If so, what sort of policy measures could help?

5. A 1 February 2001 Wall Street Journal article begins with this headline:"Latest Fed Rate Cut Takes on a Contagion of Low Confidence: Amid new Signs of Gloom, Anxiety About Recession Could Be Self-Fulfilling." How might the results 
of this experiment explain why anxiety about a recession could be self-fulfilling? How might the Federal Reserve reduce this anxiety?

\section{Feedback}

Two days after running the experiment in my intermediate macroeconomics course, I asked students to take two minutes to write down what they learned from the experiment. The following were some of their comments in response to this open-ended question.

- The business cycle depends on people's expectations of the behaviour of other firms and their interpretation of past behaviour. Communication can help eliminate fears about coming economic conditions and promote investment.

- If one person in a group is either pessimistic or random, it makes coordination difficult, if not impossible. People in groups had less faith in new entrants to the market. Communication within a group helped.

- Indirect communication seemed to have hindered aggregate profits more than help them. Once one economy did well (all four highs), it encouraged other firms in other economies to have more faith and invest at high levels.

\section{Example results}

Table 3 shows the full results for the introductory macroeconomics class whose first two rounds of results appear in Table 2 . I ran eight rounds in 42 minutes, leaving 8 minutes for a follow-up discussion. During the first seven rounds, I did not let students communicate directly with each other, although I did conduct a general discussion between rounds, as groups reported their results. In round 8,1 let students talk to each other. After the sixth round, I had Groups 1 and 3 exchange two of their members. Table 3 reports the results for all of the groups for the first six rounds, before the switching. Table 3 also includes the seventh and eighth rounds for groups 2 and 4, which had no switching. Group 5 appears in Table 3 with a new member (a late-arriving student) italicised in bold.

When I rearranged groups 1 and 3, I wanted to see what would happen to group 1, with its strong history of playing $\mathrm{H}$, when mixed with a group that had predominantly played L. So, in round 7, I combined the first two students from group 1 with the second and fourth students from group 3. Of the people coming from the low investment group, the only one who had chosen $\mathrm{H}$ in the preceding round now switched to $L$. On the other hand, one who had played $L$ in the preceding round switched to $\mathrm{H}$, a move she described as inspired by the optimism 
Table 3: Experimental Results

\begin{tabular}{|c|c|c|c|c|c|}
\hline Round & Group 1 & Group 2 & Group 3 & Group 4 & Group 5 \\
\hline 1 & L H H H & L L L L & L L L L & L L L H & L L H H \\
\hline 2 & $\mathrm{HHHH}$ & LHHL & LHLH & $\mathrm{HHLH}$ & LHLH \\
\hline 3 & $\mathrm{HHHH}$ & HLLH & L L H L & $\mathrm{HHHL}$ & LHHL \\
\hline 4 & $\mathrm{HHHH}$ & $\mathrm{HLHH}$ & HLLH & $\mathrm{HHHH}$ & LHHH \\
\hline 5 & $\mathrm{HHHH}$ & $\mathrm{HHHH}$ & L L H H & $\mathrm{LHHH}$ & $\mathrm{HHHH}$ \\
\hline 6 & $\mathrm{HHHH}$ & $\mathrm{HHHH}$ & L L H L & $\mathrm{LHHH}$ & $\mathrm{HHHH}$ \\
\hline 7 & & $\mathrm{HHHH}$ & & $\mathrm{HHHL}$ & LHLH \\
\hline 8 & & $\mathrm{HHHH}$ & & $\mathrm{HHHH}$ & $\mathrm{LHHH}$ \\
\hline
\end{tabular}

that comes from getting a fresh start. The other two continued to play L. All three who played $L$ explained that they feared their group's history of playing $L$ would scare the new members into switching to L. In fact, one of the people from the cooperative group did switch to $L$, but the other three continued to play $H$. These three playing $\mathrm{H}$ reported that they had hoped their group's history of playing $\mathrm{H}$ would encourage the new members to switch to $\mathrm{H}$.

Substituting a new student into group 5 significantly reduced its level of investment in round 7. In fact, this group was the only group that had anyone play $L$ in round 8 , when students could communicate directly with each other. In the many times I have run this experiment, both in my own fairly small classes and as a guest instructor in sections of up to 60 students, I have found that students almost always coordinate on the high investment equilibrium once they can communicate directly.

\section{Exam question}

I use the final exam question below to follow up on the experiment. A sample student answer also appears below.

Question: Consider John Maynard Keynes, who wrote about the macroeconomy during the Great Depression. Keynes believed it was possible for a recession to be caused by a general feeling of uncertainty among business owners about the likelihood that other business owners would decide to make investment expenditures. Use the results from our investment coordination experiment to explain why that feeling of uncertainty could cause and perpetuate a recession. Be sure to define investment in your explanation. 
Sample student answer: Self-fulfilling waves of optimism or pessimism can affect growth in the economy. In our experiment a firm was only likely to choose a high level of investment if it thought it was very likely for other firms to do so. Investment, which is the new capital, equipment and buildings purchased by a firm, was under-produced due to pessimistic expectations. Once one economy successfully coordinated, it made firms in another economy more optimistic about investment prospects. Some economies remained at low levels of output because firms had no reason to expect expansionary behaviour from other firms. Indirect communication helped firms communicate their expectations and reduce speculation. This occasionally spread panic when a firm communicated low expectations. Direct communication was the most effective means of coordinating firms'behaviour.

I have found, from the answers to this exam question and from general discussion, that the experiment provides a concrete and memorable example of what economists mean by investment. After the experiment, when we talk about the economic role of investment, students finally seem to understand that we mean additions to the capital stock, not purchases of financial assets. So, as a side benefit, the experiment helps students stop confusing the economics and layman's definitions of investment.

\section{Conclusion}

This experiment demonstrates how expectations about the investment climate can generate economic fluctuations. Participating in the experiment introduces students to theories of recessions as coordination failures. The follow-up discussion covers the issue of how policy makers can reduce uncertainty about the investment climate that could otherwise lead to self-fulfilling expectations of recession. 


\section{Appendix A: Instructions for the investment coordination experiment}

1. You operate a firm and have to decide when to expand your factory and buy new equipment. This investment expenditure would increase your profits if the economy as a whole were about to expand, so that people would have the income to buy your new products. The economy would be about to expand if other firms were also spending on additions to factories and equipment, thereby increasing aggregate demand. On the other hand, suppose you invest and it turns out that other firms did not invest. Then, you would have spent a considerable amount in a period of recession. Because incomes did not rise, you would have incurred a large cost without selling any more of your product. Thus, it would be a bad idea for you to invest if other firms were not simultaneously doing so.

2. I will put you in a group with three other students. Your group of four firms will represent an economy. Each of the firms in your group will simultaneously and independently choose its own level of investment. You can choose either a high level of investment $(\mathrm{H})$ or a low level of investment $(\mathrm{L})$. The chart below shows the profits your firm could earn, depending on what the other firms in your group do. You would earn these profits in the form of pieces of candy. Let's look at the first column of the chart. It shows your possible profits if no one else in your group chooses $\mathrm{H}$. In this case, the low investment by the other firms in your group generates a recession for your economy. Under these circumstances, if you choose $\mathrm{H}$, you would earn a profit of zero. If you instead choose $\mathrm{L}$, you would earn profits of 2 . Here, choosing $L$ gives you more profit because you avoid the futile expense of high investment during a recession. Similarly, the last column shows your possible profits if the three other firms in your group all choose $\mathrm{H}$. In this case, the high investment by the other firms in your group generates an economic expansion. Under these circumstances, if you choose $\mathrm{H}$, you would earn profits of 5 . If you instead choose $L$, you would earn only 4 . Here, you are better off investing at a high level to take advantage of the expanding economy. Let's also consider the middle columns. What are your possible profits if one other firm in your group chooses $\mathrm{H}$ ? How about if two other firms in your group choose $\mathrm{H}$ ?

\begin{tabular}{lllll}
\hline $\begin{array}{l}\text { Of the } 3 \text { other firms in your group, } \\
\text { the number who choose H }\end{array}$ & 0 & 1 & 2 & 3 \\
Your profits if you choose H & 0 & 1 & 3 & 5 \\
Your profits if you choose L & 2 & 3 & 4 & 4 \\
\hline
\end{tabular}


3. There will be several rounds in this experiment. In each round you will decide whether to invest at a high or low level, knowing from the chart how your profits will depend on the choices of the other members of your group. However, only one round will actually provide profits in the form of candy. At the end of the experiment, I will roll a die to determine which round that will be. So, any round could potentially provide profits, but only one round actually will.

4. In each round you will write down your investment decision on your record-keeping sheet, taking care that no one else can see it. At the point when you make your decision, you will not know what the other people in your group are choosing. In fact, you are not even allowed to talk to anyone else in the class about what they intend to choose. After everyone has made their choice, then you will find out what the other people in your group decided to do that round.

5. After a few rounds, I might switch the members of your group. I will not tell you how many rounds we will run altogether.

Appendix B: Student record-keeping sheet

\begin{tabular}{llll}
\hline $\begin{array}{l}\text { Round } \\
\text { people in your group }\end{array}$ & $\begin{array}{l}\text { Your } \\
\text { investment } \\
\text { level }\end{array}$ & $\begin{array}{l}\text { Investment levels } \\
\text { of the other people } \\
\text { in your group }\end{array}$ & $\begin{array}{l}\text { Your } \\
\text { profit }\end{array}$ \\
\hline 1 & \\
\hline 3 \\
\hline 5 \\
\hline 6 \\
\hline 7 \\
\hline 9 \\
\hline 10 \\
\hline 12 \\
\hline 15 \\
\hline 15 \\
\hline
\end{tabular}




\section{References}

Christiano, Lawrence J. and Fitzgerald, Terry J. (1998) 'The Business cycle: It's Still a Puzzle', Federal Reserve Bank of Chicago Economic Perspectives, fourth quarter, pp. 56-83.

Available at www.chicagofed.org/economic_research_and_data/economic_perspectives.cfm Federal Reserve Bank of St. Louis, National Economic Trends, http://www.stls.frb.org/publications/net/

Friedman, Daniel and Sunder, Shyam (1994) Experimental Methods: A Primer for Economists. Cambridge, UK: Cambridge University Press.

Ip, Greg and Kulish, Nicholas (2001) 'Latest Fed Rate Cut Takes on a Contagion of Low Confidence', Wall Street Journal, p. A1, 1 February.

\section{Contact details}

Prof. Denise Hazlett

Department of Economics

Whitman College

345 Boyer Ave Walla Walla

WA 9936299362

USA

Email: hazlett@whitman.edu 